\title{
The epidemiology of spinal tuberculosis in the United States: an analysis of 2002-2011 data
}

\author{
*Rafael De la Garza Ramos, MD, C. Rory Goodwin, MD, PhD, Nancy Abu-Bonsrah, BS, \\ Ali Bydon, MD, Timothy F. Witham, MD, Jean-Paul Wolinsky, MD, and Daniel M. Sciubba, MD \\ Department of Neurosurgery, Johns Hopkins University School of Medicine, Baltimore, Maryland
}

OBJECTIVE The aim of this study was to investigate the incidence of spinal tuberculosis (TB) in the US between 2002 and 2011.

METHODS The Nationwide Inpatient Sample database from 2002 to 2011 was used to identify patients with a discharge diagnosis of TB and spinal TB. Demographic and hospital data were obtained for all admissions, and included age, sex, race, comorbid conditions, insurance status, hospital location, hospital teaching status, and hospital region. The incidence rate of spinal TB adjusted for population growth was calculated after application of discharge weights.

RESULTS A total of 75,858 patients with a diagnosis of TB were identified, of whom 2789 had a diagnosis of spinal TB (3.7\%); this represents an average of 278.9 cases per year between 2002 and 2011. The incidence of spinal TB decreased significantly_from 0.07 cases per 100,000 persons in 2002 to 0.05 cases per 100,000 in 2011 ( $p<0.001$ ), corresponding to 1 case per 2 million persons in the latter year. The median age for patients with spinal TB was 51 years, and $61 \%$ were male; $11.6 \%$ were patients with diabetes, $11.4 \%$ reported recent weight loss, and $8.1 \%$ presented with paralysis. There were 619 patients who underwent spinal surgery for TB, with the most common location being the thoracolumbar spine ( $61.9 \%$ of cases); $50 \%$ of patients had instrumentation of 3 or more spinal segments.

CONCLUSIONS During the examined 10 -year period, the incidence of spinal TB was found to significantly decrease over time in the US, reaching a rate of 1 case per 2 million persons in 2011. However, the absolute reduction was relatively small, suggesting that although it is uncommon, spinal TB remains a public health concern and most commonly affects male patients approximately 50 years of age. Approximately $20 \%$ of patients with spinal TB underwent surgery, most commonly in the thoracolumbar spine.

https://thejns.org/doi/abs/10.3171/2016.9.SPINE16174

KEY WORDS tuberculosis; spine; Pott's disease; epidemiology; incidence; surgery; infection

$\mathrm{S}$ PINAL tuberculosis (TB) is a known cause of spinal deformity and paraplegia. First described in the modern era by English surgeon Percival Pott in 1779 (i.e., Pott's disease), ${ }^{20}$ it is currently regarded as a disease affecting people in the developing world. ${ }^{7}$ Nevertheless, TB remains a problem in developed regions such as Europe and the US.6.16,25 In 2014 alone, a total of 9421 new cases of TB were reported in the US, corresponding to an incidence of 2.96 cases per 100,000 persons. ${ }^{5}$

Pott was the first to recognize the link between TB, ky- phosis, and paraplegia. ${ }^{12}$ Whereas spinal TB affects mostly children in developing nations, it is a disease of the elderly in the developed world? Pott's disease develops after hematogenous spread of Mycobacterium tuberculosis from a primary site (typically the lungs), which leads to destruction of the intervertebral disc and vertebral body. ${ }^{11}$ This results in a pathological compression fracture, vertebral wedging, and kyphoscoliosis, which in turn may lead to neurological deficits due to spinal cord compression., ${ }^{2,14,17}$

Despite multiple epidemiological studies examining

ABBREVIATIONS ICD-9 = International Classification of Diseases, 9th Revision; LOS = length of stay; NIS = Nationwide Inpatient Sample; TB = tuberculosis. SUBMITTED February 22, 2016. ACCEPTED September 2, 2016.

INCLUDE WHEN CITING Published online December 16, 2016; DOI: 10.3171/2016.9.SPINE16174.

* Drs. De la Garza Ramos and Goodwin contributed equally to this work. 


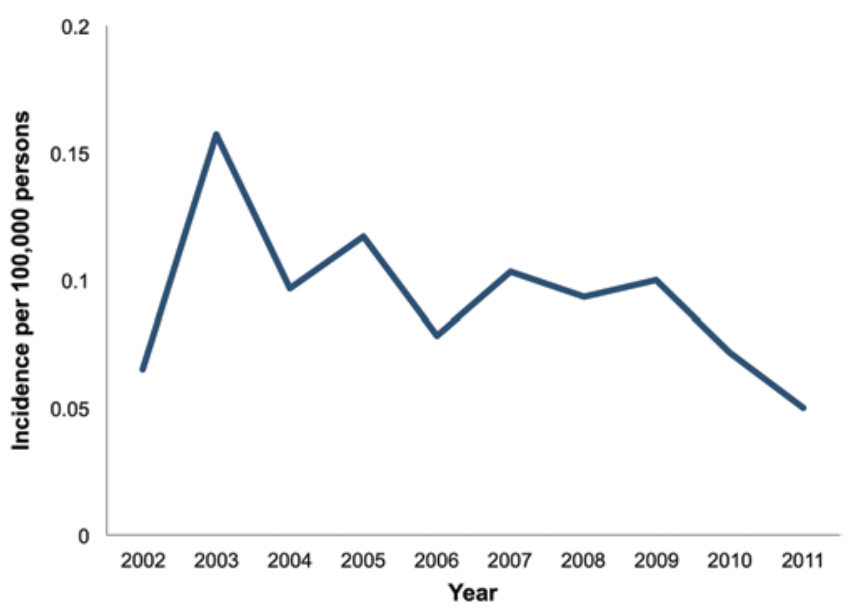

FIG. 1. Graph showing the population growth-adjusted incidence rate of patients with a discharge diagnosis of spinal TB in the US from 2002 to 2011. After a peak in 2003, the incidence was found to decrease significantly over time $(p<0.001)$. Figure is available in color online only.

TB, there are limited data on the prevalence of Pott's disease in the US., ${ }^{913}$ The aim of this study is to investigate the incidence of spinal TB in the American population between 2002 and 2011, using a large nationwide database.

\section{Methods}

\section{Study Design}

This epidemiological study used the Nationwide Inpatient Sample (NIS) database records of patients treated between 2002 and 2011. Developed by the Healthcare Cost and Utilization Project, the NIS is the largest inpatient database in the US, containing hospital admission information from a $20 \%$ sample of community hospitals across the country. This $20 \%$ sample corresponds to more than 8 million hospital stays annually and contains diagnostic and procedure data in the form of International Classification of Diseases, 9th Revision (ICD-9) codes.

\section{Patient Sample and Inclusion Criteria}

All patients with a diagnosis of "tuberculosis" were identified using the Clinical Classifications Software code \#1. Patients with spinal TB were then identified via use of ICD-9 codes 015.00, 015.01, 015.02, 015.03, 015.04, 015.05 , and 015.06. Patients who underwent spinal fusion were identified via ICD-9 procedural codes 81.00-81.09.

\section{Recorded Variables}

Documented admission information included the following: patient age; sex; race; comorbid conditions; primary payer (insurance); hospital region (Northeast, Midwest or North Central, South, or West); hospital teaching status; hospital location (urban vs rural); in-hospital mortality rate; and length of stay (LOS). For patients who underwent spinal surgery, the following complications were recorded: neurological complications; iatrogenic stroke; respiratory complications (including respiratory failure); pulmonary embolism; deep venous thrombosis; myocardial infarction; acute kidney injury; urinary tract infection; Clostridium difficile; paralytic ileus; other gastrointestinal

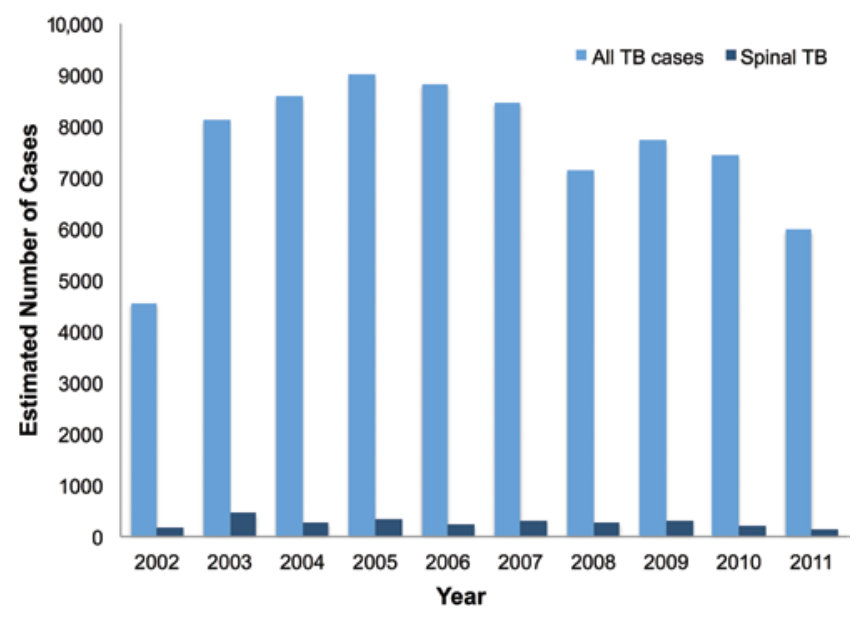

FIG. 2. Bar graph showing the proportion of patients with spinal TB among all TB cases. The proportion was found to decrease significantly, from $4.1 \%$ in 2002 to $2.6 \%$ in $2011(p<0.001)$. Figure is available in color online only.

complication; surgical site infection; meningitis; pneumonia; and incidental durotomy. Hospital charges (excluding professional fees) were also recorded and reported in 2016 US dollars.

\section{Statistical Methods}

National estimates for spinal TB cases were calculated after application of discharge weights supplied by the NIS. Given that this database is a $20 \%$ sample, roughly a 5-fold multiplication will give the total number of estimated cases in the US per year. US population data for each year were obtained from the website of the US Census Bureau (http://www.census.gov/popest/data/historical/ index.html). Incidences for any given year were adjusted for population growth by dividing the estimate of each diagnosis (from the NIS) by the total population estimate from the US Census Bureau. ${ }^{4}$ A simple linear regression was done to analyze trends over time. Statistical analyses were performed in STATA 12 SE (StataCorp). A probability value $<0.05$ was considered statistically significant.

\section{Results}

Between 2002 and 2011, a total of 75,858 patients with a diagnosis of TB were identified, of whom 2789 had a diagnosis of spinal TB (3.7\%). The average annualized rate of spinal TB was 278.9 cases per year. During the 10-year period examined, the incidence of spinal TB decreased significantly, from 0.07 cases per 100,000 persons in 2002 to 0.05 per 100,000 in 2011 (Fig. 1). In 2011, this incidence corresponded to 1 case per every 2 million persons.

The proportion of spinal TB cases among all TB cases was $4.1 \%, 5.6 \%, 3.3 \%, 3.8 \%, 2.6 \%, 3.7 \%, 4.0 \%, 4.0 \%$, $3.0 \%$, and $2.6 \%$ yearly between 2002 and 2011 (Fig. 2). A summary of spinal TB cases is shown in Table 1 . The median age of patients was 51 years, and $61 \%$ were male. There was an almost equal proportion of Caucasian (24.0\%), African American (23.8\%), and Hispanic patients (23.2\%), and a smaller proportion of Asian/Pacific Islanders (18.8\%) and others (10.2\%). The 5 most common 
TABLE 1. Summary of characteristics in 2789 patients with a diagnosis of spinal TB

\begin{tabular}{|c|c|}
\hline Parameter & Value \\
\hline No. of cases & 2789 \\
\hline Median age in yrs (IQR) & $51(35-65)$ \\
\hline Age $>65$ yrs $(\%)$ & 24.4 \\
\hline \multicolumn{2}{|l|}{$\operatorname{Sex}(\%)$} \\
\hline Female & 39.0 \\
\hline Male & 61.0 \\
\hline \multicolumn{2}{|l|}{ Race (\%) } \\
\hline Caucasian & 24.0 \\
\hline African American & 23.8 \\
\hline Hispanic & 23.2 \\
\hline Asian or Pacific Islander & 18.8 \\
\hline Other & 10.2 \\
\hline \multicolumn{2}{|l|}{ Comorbidities (\%) } \\
\hline Alcohol abuse & 3.0 \\
\hline Chronic lung disease & 7.7 \\
\hline Diabetes & 11.6 \\
\hline Drug abuse & 5.5 \\
\hline Hypertension & 28.6 \\
\hline Liver disease & 4.9 \\
\hline Obesity & 2.8 \\
\hline Renal failure & 5.6 \\
\hline Paralysis & 8.1 \\
\hline Weight loss & 11.4 \\
\hline HIV positive & 4.0 \\
\hline Malnutrition & 11.6 \\
\hline \multicolumn{2}{|l|}{ Insurance status (\%) } \\
\hline Medicare & 25.8 \\
\hline Medicaid & 24.4 \\
\hline Private insurance & 26.2 \\
\hline Self-pay & 11.4 \\
\hline Other & 12.2 \\
\hline \multicolumn{2}{|l|}{ Hospital region (\%) } \\
\hline Northeast & 22.6 \\
\hline Midwest or North Central & 10.1 \\
\hline South & 39.9 \\
\hline West & 27.4 \\
\hline Teaching hospital (\%) & 76.8 \\
\hline Urban hospital (\%) & 97.7 \\
\hline In-hospital mortality (\%) & 1.9 \\
\hline Median LOS in days (IQR) & $10(6-19)$ \\
\hline
\end{tabular}

$\mathrm{IQR}=$ interquartile range.

comorbid conditions were hypertension (28.6\%), diabetes $(11.6 \%)$, malnutrition (11.6\%), weight loss (11.4\%), and paralysis $(8.1 \%) ; 4.0 \%$ of patients were HIV positive. More than one-fourth $(26.2 \%)$ of patients had private insurance, 25.8\% had Medicare, 24.4\% had Medicaid, $12.2 \%$ had another form of insurance, and $11.4 \%$ were categorized as self-pay.

The most common hospital region was the South
TABLE 2. Summary characteristics of 619 patients who underwent surgery for spinal TB between 2002 and 2011

\begin{tabular}{lc}
\hline \multicolumn{1}{c}{ Parameter } & Value \\
\hline No. of cases & 619 \\
\hline Median age in yrs (IQR) & $52(35-66)$ \\
\hline Age $>65$ yrs (\%) & 26.2 \\
\hline Sex (\%) & 44.4 \\
\hline Female & 55.6 \\
\hline Male & \\
\hline Surgery location (\%) & 11.1 \\
\hline Cervical & 61.9 \\
\hline Thoracolumbar & 27.0 \\
\hline Lumbosacral & \\
\hline Approach (\%) & 38.9 \\
\hline Posterior only & 26.6 \\
\hline Anterior only & 34.5 \\
\hline Combined & \\
\hline No. of instrumented levels (\%) & 50.0 \\
\hline 1-2 & 42.0 \\
\hline $3-7$ & 8.0 \\
\hline$\geq 8$ & 38.8 \\
\hline Complication rate (\%) & 3.2 \\
\hline In-hospital mortality (\%) & $16(10-24)$ \\
\hline Median LOS in days (IQR) & \\
\hline
\end{tabular}

(39.9\%), followed by the West $(27.4 \%)$, the Northeast (22.6\%), and the Midwest or North Central (10.1\%). A majority of patients were admitted to urban hospitals (97.7\%) with teaching status $(76.8 \%)$. The in-hospital mortality rate was $1.9 \%$, and the median LOS was 10 days.

There were 619 patients who underwent spinal surgery for TB (22.2\% of spinal TB cases) (Table 2), with a median age at surgery of 52 years; $55.6 \%$ were male. The most common location was the thoracolumbar spine $(61.9 \%$ of cases), and $50 \%$ of patients had instrumentation of 3 or more spinal segments. The surgical approach was posterior alone in $38.9 \%$ of cases, anterior alone in $26.6 \%$, and combined in $34.5 \%$. The mortality rate was $3.2 \%$, and the median LOS was 16 days. The percentage of patients who developed at least 1 in-hospital complication was $38.8 \%$. The proportion of patients with spinal TB who required surgery was $23.1 \%, 20.0 \%, 13.6 \%, 16.9 \%, 23.4 \%, 25.4 \%$, $32.2 \%, 16.4 \%, 20.5 \%$, and $18.9 \%$ between 2002 and 2011 $(p=0.426)$. The average adjusted hospital charges for patients who required surgery were $\$ 223,780 \pm \$ 168,361$, versus $\$ 55,363 \pm \$ 72,998$ for patients with spinal TB who did not require surgery $(\mathrm{p}<0.001)$.

\section{Discussion}

Although the first modern description of spinal TB was published in 1779, the first evidence of this disease dates to a skeleton from approximately $5000 \mathrm{BC} .{ }^{12}$ Nowadays, Pott's disease mostly affects children and young adults in developing countries, ${ }^{17,18}$ and may cause severe spinal deformity and associated paraparesis secondary to cord compression 


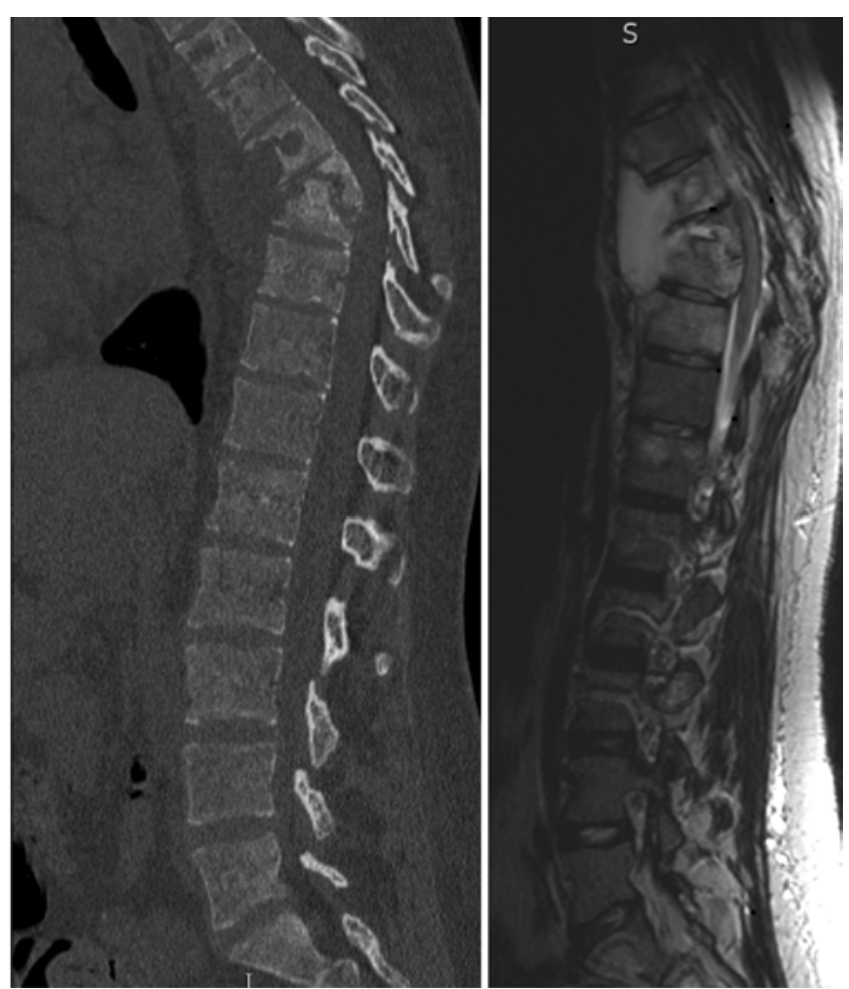

FIG. 3. A 21-year-old woman, an immigrant, presented to our institution with a severe kyphotic deformity of the thoracic spine and mild paraparesis secondary to TB. Left: Preoperative CT scan of the thoracic spine showing destruction of T-7, T-8, and T-9, with severe focal kyphosis. Right: Preoperative T2-weighted MR image showing focal kyphotic deformity and spinal cord compression.

(Fig. 3). Nonetheless, spinal TB is still seen in vulnerable populations in the developed world, including Europe and the US. The aim of this study was to investigate the incidence of Pott's disease in America, and although we found a statistically significant decrease between 2002 and 2011, the absolute decrease was relatively small (from 0.07 per 100,000 persons to 0.05 per 100,000 ).

In 2002, there were an estimated total of 188 cases of spinal TB (0.07 per 100,000 persons), which peaked to 457 in 2003 (0.16 per 100,000 persons). Afterward, the total number of cases gradually decreased, reaching 155 cases in 2011, which corresponds to 0.05 per 100,000 , or 1 per 2 million persons. Patients with spinal TB were on average 51 years of age, and $61 \%$ were male. Commensurate with our findings, Brashear and Rendelman also reported an average age of 51 years in a series of patients with spinal TB from the southern US. ${ }^{3}$ Schlesinger et al. examined 12 patients with Pott's disease from a New Jersey hospital (Northeast US), finding a mean age of 40 years and male predominance $(58 \%){ }^{22}$

The prevalence of HIV positivity was $4.0 \%$ in the present study, and $5.5 \%$ of patients had a history of drug abuse. Similar to these findings, Fuentes Ferrer et al. performed a systematic review of spinal TB case series, finding a median prevalence of HIV of $7.5 \% .{ }^{10}$ On the other hand, more than one-tenth of patients in our study presented with diabetes, malnutrition, and/or weight loss, all of which have been associated with spinal TB..$^{10,15,23}$
Interestingly, the most common hospital regions were the southern US in almost $40 \%$ of cases, followed by the western US in $27.4 \%$. Similar to these findings, the official report from the Centers for Disease Control and Prevention found a higher than average incidence for states such as Texas, Florida, Georgia, California, and Nevada. ${ }^{5}$ These aforementioned states had an incidence of $>3$ cases per 100,000 persons, which was higher than the national average of $\leq 3$ cases per 100,000 . Although there is no single explanation for these findings, contributing factors to the observed higher incidence in these states include a larger proportion of patients who were foreign born and higher rates of homelessness, among others. ${ }^{1}$

In the present study, $22.2 \%$ of spinal TB cases required surgery, with the most common location being the thoracolumbar spine in $61.9 \%$ of cases, followed by the lumbosacral spine in $27.0 \%$, and the cervical spine in $11.1 \%$. With the availability of systemic antituberculous therapy, surgery for spinal TB is reserved for patients with neurological deficits, instability due to kyphoscoliotic deformity, drug-resistant TB, or those in whom there is a high risk of paralysis. ${ }^{21}$ In a randomized controlled trial performed in the United Kingdom, researchers randomized patients with spinal TB to 1 of 3 groups: A) surgery plus 6 months of isoniazid plus rifampicin; B) isoniazid plus rifampicin for 6 months; or C) isoniazid plus rifampicin for 9 months..$^{19}$ The authors found rates of "favorable status" in $90 \%, 94 \%$, and $99 \%$ of patients in Groups A, B, and C, respectively. Nevertheless, patients younger than 15 years of age with kyphotic deformity greater than $30^{\circ}$ did not experience as much improvement with medical therapy alone. Surgical techniques include posterior decompression and stabilization, anterior decompression and stabilization, and combined approaches (either posterior-anterior or anterior-posterior) with stabilization (Fig. 4). ${ }^{21}$

Although spinal TB is considered predominantly a disease affecting people in the developing world, the findings in the present study suggest that it is still seen in the US. The incidence of Pott's disease has slightly decreased, and the 2011 estimate was of 1 case per 2 million. Patients at the highest risk for TB (immunocompromised, malnourished, living in poverty, with a history of traveling to high-prevalence areas, and others) who present with back pain should be evaluated for the possibility of Pott's disease.

\section{Study Limitations}

This study has several limitations. Although the NIS database has been used in multiple studies examining the epidemiology and trends of various spinal disorders, ${ }^{4,8,24}$ its administrative nature carries a risk of coding bias. Given that it is an inpatient database, spinal TB cases treated in an outpatient setting are not captured, and thus the true incidence of spinal TB may be higher. The lack of data on functional status, degrees of kyphosis, or long-term outcome is also an important limitation. Nevertheless, this is one of the first studies to report the incidence of Pott's disease in a developed country, and the use of such a large database allows for adequate estimation of the incidence of rare conditions. 

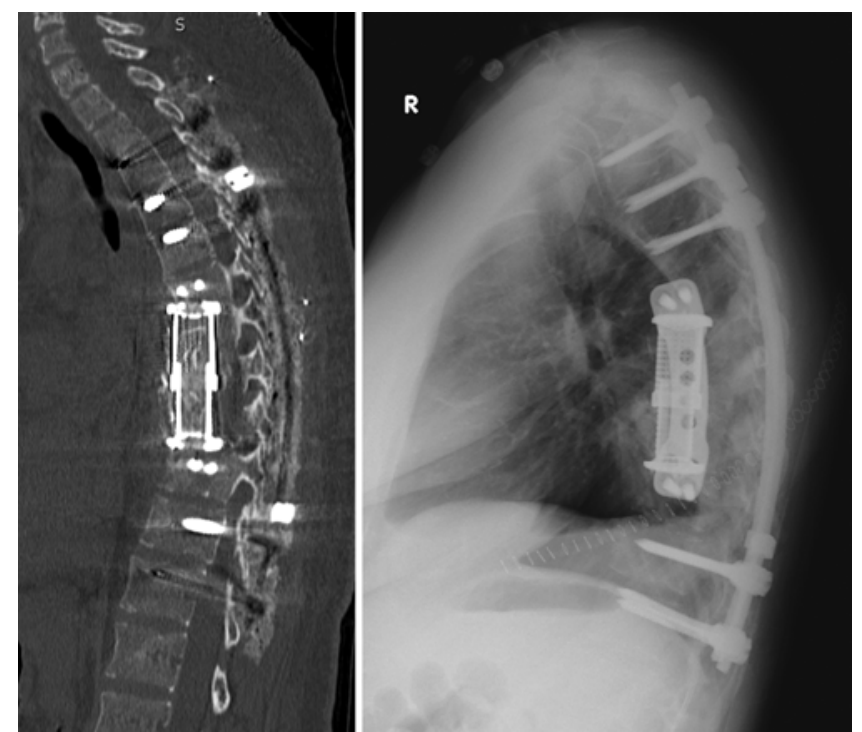

FIG. 4. The same patient depicted in Fig. 3 underwent a combined anterolateral-posterior approach. The first stage consisted of a rightsided thoracotomy, resection of rib, and corpectomy of T-7, T-8, and T-9. This was followed by placement of a distractible cage, plate, and screws, reduction of kyphosis, and arthrodesis using allograft and local autograft from T-6 to T-10. This was followed by drainage of abscess. The second stage consisted of pedicle screw instrumentation from T-3 to T-12 and arthrodesis performed using locally obtained autograft, allograft, and demineralized bone matrix. Left: Postoperative CT image showing the distractible cage between T-6 and T-10. Right: Postoperative radiograph showing anterior and posterior reconstruction.

\section{Conclusions}

In this study of a nationwide database, the incidence of spinal TB was found to decrease significantly over time in the US, reaching a rate of 1 case per 2 million persons in 2011. However, the absolute reduction was relatively small, suggesting that although it is uncommon, spinal TB remains a public health concern most commonly affecting male patients approximately 50 years of age. Of all spinal TB cases, approximately $20 \%$ required surgery-most commonly in the thoracolumbar spine.

\section{References}

1. Alami NN, Yuen CM, Miramontes R, Pratt R, Price SF, Navin TR: Trends in tuberculosis-United States, 2013. MMWR Morb Moral Wkly Rep 63:229-233, 2014

2. Boachie-Adjei O, Papadopoulos EC, Pellisé F, Cunningham ME, Perez-Grueso FS, Gupta M, et al: Late treatment of tuberculosis-associated kyphosis: literature review and experience from a SRS-GOP site. Eur Spine J 22 (Suppl 4):641-646, 2013

3. Brashear HR, Rendelman DA: Pott's paraplegia. South Med J 71:1379-1382, 1978

4. Bydon M, De la Garza-Ramos R, Macki M, Desai A, Gokaslan AK, Bydon A: Incidence of sacral fractures and inhospital postoperative complications in the United States: an analysis of 2002-2011 data. Spine (Phila Pa 1976) 39:E1103-E1109, 2014

5. Centers for Disease Control and Prevention: Tuberculosis (TB) Data and Statistics. Centers for Disease Control and Prevention. (http://www.cdc.gov/tb/statistics/default.htm) [Accessed October 19, 2016]
6. Dara M, Dadu A, Kremer K, Zaleskis R, Kluge HH: Epidemiology of tuberculosis in WHO European Region and public health response. Eur Spine J 22 (Suppl 4):549-555, 2013

7. Dass B, Puet TA, Watanakunakorn C: Tuberculosis of the spine (Pott's disease) presenting as 'compression fractures'. Spinal Cord 40:604-608, 2002

8. De la Garza-Ramos R, Samdani AF, Sponseller PD, Ain MC, Miller NR, Shaffrey CI, et al: Visual loss after corrective surgery for pediatric scoliosis: incidence and risk factors from a nationwide database. Spine J 16:516-522, 2016

9. Friedman B: Chemotherapy of tuberculosis of the spine. J Bone Joint Surg Am 48:451-474, 1966

10. Fuentes Ferrer M, Gutiérrez Torres L, Ayala Ramírez O, Rumayor Zarzuelo M, del Prado González N: Tuberculosis of the spine. A systematic review of case series. Int Orthop 36:221-231, 2012

11. Golden MP, Vikram HR: Extrapulmonary tuberculosis: an overview. Am Fam Physician 72:1761-1768, 2005

12. Gruber P, Boeni T: History of spinal disorders, in Boos N, Aebi M (eds): Spinal Disorders: Fundamentals of Diagnosis and Treatment. Berlin: Springer, 2008

13. Leibert E, Schluger NW, Bonk S, Rom WN: Spinal tuberculosis in patients with human immunodeficiency virus infection: clinical presentation, therapy and outcome. Tuber Lung Dis 77:329-334, 1996

14. Liu Z, Wang X, Xu Z, Zeng H, Zhang P, Peng W, et al: Two approaches for treating upper thoracic spinal tuberculosis with neurological deficits in the elderly: A retrospective casecontrol study. Clin Neurol Neurosurg 141:111-116, 2016

15. Mulleman D, Mammou S, Griffoul I, Avimadje A, Goupille P, Valat JP: Characteristics of patients with spinal tuberculosis in a French teaching hospital. Joint Bone Spine 73:424427, 2006

16. Murray CJ, Ortblad KF, Guinovart C, Lim SS, Wolock TM, Roberts DA, et al: Global, regional, and national incidence and mortality for HIV, tuberculosis, and malaria during 1990-2013: a systematic analysis for the Global Burden of Disease Study 2013. Lancet 384:1005-1070, 2014

17. Pang X, Li D, Wang X, Shen X, Luo C, Xu Z, et al: Thoracolumbar spinal tuberculosis in children with severe post-tubercular kyphotic deformities treated by single-stage closing-opening wedge osteotomy: preliminary report a 4-year follow-up of 12 patients. Childs Nerv Syst 30:903909, 2014

18. Papadopoulos EC, Boachie-Adjei O, Hess WF, Sanchez Perez-Grueso FJ, Pellisé F, Gupta M, et al: Early outcomes and complications of posterior vertebral column resection. Spine J 15:983-991, 2015

19. Parthasarathy R, Sriram K, Santha T, Prabhakar R, Somasundaram PR, Sivasubramanian S: Short-course chemotherapy for tuberculosis of the spine. A comparison between ambulant treatment and radical surgery-ten-year report. J Bone Joint Surg Br 81:464-471, 1999

20. Pott P: Remarks on that kind of palsy of the lower limbs, which is frequently found to accompany a curvature of the spine, and is supposed to be caused by it. London: $\mathrm{J}$. Johnson, 1779

21. Rasouli MR, Mirkoohi M, Vaccaro AR, Yarandi KK, Rahimi-Movaghar V: Spinal tuberculosis: diagnosis and management. Asian Spine J 6:294-308, 2012

22. Schlesinger N, Lardizabal A, Rao J, Rao J, McDonald R: Tuberculosis of the spine: experience in an inner city hospital. $\mathbf{J}$ Clin Rheumatol 11:17-20, 2005

23. Tuli SM: Tuberculosis of the spine: a historical review. Clin Orthop Relat Res 460:29-38, 2007

24. Yoshihara H, Yoneoka D: Trends in the surgical treatment for spinal metastasis and the in-hospital patient outcomes in the United States from 2000 to 2009. Spine J 14:1844-1849, 2014 
25. Young KH, Ehman M, Reves R, Peterson Maddox BL, Khan A, Chorba TL, et al: Tuberculosis contact investigationsUnited States, 2003-2012. MMWR Morb Mortal Wkly Rep 64:1369-1374, 2016

\section{Disclosures}

Dr. Sciubba has consulting relationships with Medtronic, Globus, DePuy Synthes, and Orthofix. Dr. Goodwin is a UNCF (United Negro College Fund)/Merck Postdoctoral Fellow and has received an award from the Burroughs Wellcome Fund and the Johns Hopkins Neurosurgery Pain Research Institute. Dr. Bydon received support of a non-study-related clinical or research effort that he oversaw from DePuy Spine, and he is on the advisory board for MedImmune. Dr. Witham received support of a non-study-related clinical or research effort that he oversaw from Eli Lilly and Co. and from the Gordon and Marilyn Macklin Foundation. Dr. Wolinsky is a consultant for Medtronic, DePuy Synthes, Globus, Orthofix, and Stryker.

\section{Author Contributions}

Conception and design: Sciubba, De la Garza Ramos. Acquisition of data: Sciubba, De la Garza Ramos, Goodwin. Analysis and interpretation of data: all authors. Drafting the article: all authors. Critically revising the article: Sciubba, De la Garza Ramos,

Bydon, Witham, Wolinsky. Reviewed submitted version of manuscript: all authors. Approved the final version of the manuscript on behalf of all authors: Sciubba. Statistical analysis: Sciubba, De la Garza Ramos, Goodwin, Abu-Bonsrah. Study supervision: Sciubba, Bydon, Witham, Wolinsky.

\section{Supplemental Information}

\section{Current Affiliations}

Dr. De la Garza Ramos: Department of Neurological Surgery, Montefiore Medical Center/Albert Einstein College of Medicine, Bronx, NY.

\section{Correspondence}

Daniel M. Sciubba, Department of Neurosurgery, The Johns Hopkins Hospital, 600 North Wolfe St., Meyer 5-185, Baltimore, MD 21287. email: dsciubb1@jhmi.edu. 